\title{
Theft and Vandalism Control Measures on Building Sites in Lagos, Nigeria
}

\author{
Oluranti Farinloye ${ }^{1}$, Kole Odusami ${ }^{2}$, and Yewande Adewunmi ${ }^{3}$ \\ ${ }^{1}$ Assistant Lecturer, Department of Building, University of Lagos, Akoka, Lagos state, Nigeria, \\ ofarinloye@unilag.edu.ng (corresponding author). \\ ${ }^{2}$ Professor, Department of Building, University of Lagos, Akoka, Lagos state, Nigeria, ktodusami@yahoo.com \\ ${ }^{3}$ Assistant Lecturer, Department of Estate Management, University of Lagos, Akoka, Lagos state, Nigeria, \\ yewande_adewunmi@yahoo.com
}

Project Management

Received January 13, 2012; received revisions January 31, 2012; April 5, 2012; April 10, 2012; May 15, 2012; June 2, 2012; accepted June 7, 2012

Available online September 21, 2012

\begin{abstract}
Problems of theft and vandalism is paramount issues related to building sites. The incidence of theft and vandalism sometimes depend on the nature of construction work and these vary among housing developments, roads and highways construction, dam structures, airport, and stadia construction. This study investigates the nature of theft $\&$ vandalism and security control on building site to curb the endemic effect through diversity of security technologies. A purposive sampling technique was adopted for the study. Opinion survey questionnaires were administered to construction professionals in the three categories of construction firms; large construction, medium construction and small construction firms and literature was also reviewed. The data collected was analysed using both descriptive and inferential statistics. Study revealed that more theft and vandalism are experienced large construction firms than medium and small firms. Construction professionals agree to identify causes of losses and considered all security component/ measures to be important.
\end{abstract}

Keywords: Construction site, security control, theft, vandalism.

\section{Introduction}

Thieves and vandals can directly impact the success of a project and diminish the potential profitability of the project under construction. It is a considerable problem in the construction industry and will continue to be a threat (Farinloye et al., 2009). Theft is more costly to large sized firms than smaller firms, but vandalism is more costly for smaller firms and this occurs despite the fact that larger firms use a greater number of measures to combat theft and vandalism on their construction sites (Berg, 2005). The Annual losses to the building industry as a result of criminal activities run into millions of dollars and, according to most industry stakeholders, losses are escalating each year (BSCP, 2002).

Security is the protection of people and things such as buildings and sites from harm, theft, or sabotage and encompasses several components such as physical, personnel, investigations, awareness and information security (Arata, 2005) cited in (Yulia, 2008). Crime prevention on construction sites has become a major concern for many building contractors and losses from theft and vandalism in Nigeria can make the difference between making a profit and incurring a loss on a job. A stolen piece of equipment or material can shut the job down temporarily and Insurance costs are bound to rise (BSCP, 2002). Vandalism is usually a nuisance crime on construction job sites and most times contractors does not see it to be a serious loss or threat. Nonetheless, any loss on construction job site detracts organisation profits and the threat of vandalism cannot but be taken serious. The occurrence of theft and vandalism in the recent times has increased drastically and is regarded as an endemic problem confronting the construction industry.

In general, even in advanced countries building site has always been a target for thieves and vandals because valuable items are left on site over a long period, site location are easily approachable both night and on weekends and, most times security system are defeated, ineffective or extremely expensive for contractors to buy (Premo, n.d.). Control and management is often difficult particularly on large construction sites, where workers are often casual labourers and not easy to keep track of, and where large amounts of equipment, tools and building materials are difficult to monitor. These problems are due to: lack of new innovation on security measures on site, lack of motivating incentives, welfare facilities for staff, economy deterioration and high unemployment climbs. 
In addition, many contractors do not report the theft of equipment and tools to the police if the object stolen is valued less than the company's insurance deductible amount and in terms of vandalism, numerous contractors consider an act of vandalism to be "part of the job" if it is not of an extraordinary cost. Theft, vandalism and insecurity is a serious problem in the construction industry and losing equipment, materials, and tools as a result of theft, costs the average contractor thousands of dollar each year. The drive to squeeze out intruders, thieves, and vandals and enforce measures to improve jobsite security has been on the increase (Lang, 2008) In Lagos, Nigeria incidence of theft and vandalism is evident on building sites as found by Farinloye et al., (2009) been a threat that affected performance and potential profitability of projects under construction. However, no study addresses the causes of losses and importance of component of security control on building site in Lagos, Nigeria. In the light of the discussion this paper seeks to answer the following research questions

1. What is the incidence of theft and vandalism in Lagos building sites?

2. What are the causes of losses on building sites in Lagos, Nigeria?

3. What are the measures employed to reduce or eliminate theft and vandalism acts?

4. What is the importance of the component of security control measures on building site?

Hence this paper examine the incidence of theft and vandalism, causes of losses on construction site, measures to employed to reducing or eliminating thefts and acts of vandalism and the importance of component of security control on construction site.

\section{Literature Review}

\subsubsection{Theft}

Theft is defined as the unauthorized removal of any material or equipment from a job site (Gransberg et al., 2006) cited in Yulia (2008). A person is guilty of theft if he dishonestly appropriates property belonging to another with the intention of permanently depriving the other of it. According to oxford advanced learner's dictionary 6th ed. (2000) theft is the crime of stealing something from a person or place.

\subsubsection{Vandalism}

Vandalism is the crime of destroying or damaging something or property deliberately and for no good reason. Vandalism is generally a nuisance crime on construction site, broken glass, graffiti, destruction of in-place materials and damage to construction equipment. Cohen (1984) cited in Tamar and David (2003) suggests that acts of vandalism are motivated by anger, boredom, catharsis, erosion of already damaged objects, or aesthetic factors.

\subsubsection{Theft in the building industry}

Clarke and Goldstern (2003) recognized three forms of theft on construction site, this include theft by workers of tools and materials, after hours pilfering of lumber and other materials and theft by habitual offenders. Theft of heavy machinery is well organized, according to supervisory special agent, Tracey Reinhold, of Federal Bureau of Investigation theft transportation crimes unit in
Washington. He claims that thieves "usually set out to steal a specific piece of equipment that has a specific cash value or for which a buyer has been identified prior to the theft" (Rawl, 2000) cited in (Montealegre, 2003). Security on building sites is an often-ignored facet of construction projects and it is important for contractors to recognize that construction sites are a natural point of curiosity. A typical construction site turns into a "ghost town" after 4 or 5 p.m. and this often makes it vulnerable to individuals familiar with the jobsite (Gardner, 2003; Berg, 2003; Yulia, 2008) to commit theft and vandalism.

Cunius and Rost of the Charlotte-Mecklenburg police department, Charlotte, Nc, United states in 2005 in their patrol work learned from talking with site supervisors while on patrol that the costs of break-ins were of comparatively little concern to most of them. Only the small builders, who saw their profits being eroded, were seriously concerned about the loss of the appliances and the costs of repairing the damage. For others, when losses climbed above budgeted amounts, these could be passed on to future customers in the form of higher prices (BSCP, 2002).

In addition, a spokesman for the National Association of Home Builders, Northwest, Washington, DC stated that "Statistics on theft and vandalism are hard to nail down because many incidents simply are not reported". According to Shayne Garber a construction manager in Kimball Hill Homes, Florida, United states stated that as a company, they decided to bring a Security company in to actively execute security monitoring on their site. They plan a coverage area, in which the installer professionally and competently activates security cameras and other security facilities on site. The lack of security control to combat these losses indicates that contractors need to expand their understanding of the problem and to implement practical solutions (Rowerdink, 1987) cited in (Montealegre, 2003).

Tool theft has been a significant issue for construction companies, and the arrival of sites on the Internet has made the problem worse." Websites can be used to quickly sell stolen products. This practice is becoming a Steal-to-Order Business. Another target, besides tools, is heavy machinery, such as bobcats and tractors. Denis Taylor and Co, Duluth, GA, United states, a company that rents larger equipment and operators to many Atlanta contracting firms reported that about ten machines were stolen in the past 25 years (Bond, 2000; Pfeffer, 2001) cited (Montealegre, 2003). These are expensive losses Bobcats cost about $\$ 30,000$ and crawler loader backhoes cost around $\$ 80,000$. The loss of materials and equipment due to theft and vandalism has been estimated in the United States to have exceeded \$1 billion annually. A study conducted by Construction Equipment magazine in the year 2000 found that $73 \%$ of the participants within construction industry listed construction equipment theft as a critical issue (Stewart, 2000) cited (Yulia, 2008). Reports from the Insurance Services Office, Inc. (ISO) showed theft value of equipment to have increase up to $20 \%$ since 1996 and as the most common cause of loss of heavy equipment, representing more than $50 \%$ of all causes of loss. More disturbing fact is that ISO estimates that only $10-15 \%$ of stolen equipment is ever recovered in the United States (Cueno, 2001; National Equipment Register, Inc., 2002; Yulia, 2008). It was also reported that most theft item recoveries occurred in Florida at 35\%; 
California at $17 \%$; Georgia at $12 \%$; Texas and Arizona each at 10\%; Massachusetts at 7\%; New York at 5\%; Michigan and Connecticut each at 2\% (McDowall, 2002; Berg, 2003)

\subsubsection{Vandalism in the building industry}

Vandalism is a nuisance crime on construction sites that causes serious losses for most contractors. It involves broken glass, graffiti, destruction of in-place materials and damage to construction equipment are types of vandalism that can occur on building sites. The most suspected culprits are people that live in the neighborhood, strangers, disgruntled workers, fired workers and site visitors.

Terminations of jobs alone account for many of the causes of vandalism that have been prosecuted. At any point when or where workers jobs are terminated, job site should be made extra secured with the use of additional security and possibly the changing of locks (Moorhouse, 2000).

Montealegre (2003) carried out a survey in Florida, USA on the estimated value of vandalism incidents. Based on 110 responses, the mean estimated value was $\$ 3,767$ and the median estimated value was $\$ 300$. In addition the minimum value of these incidents according to the data was $\$ 50$ and the maximum was $\$ 100,000$ in three years.
Companies experienced about $\$ 100,000$ in losses reported from 233 cases of vandalism per year. According to the findings, $44.5 \%$ of the companies in the study had not experienced any incident over the same period of time. However, $23.7 \%$ have suffered losses that cost between $\$ 1$ and $\$ 1,000$ during the same period (see Fig. 1).

In summary, the graph indicates that $44.5 \%$ of the homebuilders did not have any vandalism incidents on their jobsites; nevertheless, another $(23.7+21.8) 45.5 \%$ experienced losses estimated at less than $\$ 5,000$, and the remaining $10.3 \%$ experienced vandalism losses exceeding $\$ 5,000$. Montealegre further examined the data to determine the frequency of the types of vandalism acts on construction sites.

Fig. 2 illustrated the most frequent acts of vandalism. "Broken glass" accounted for the largest percentage, $65.8 \%$ of the six types of incidents examined in this study. "Destruction of in-place materials" accounted for $57.9 \%$ of the responses. "Graffiti" was reported by $40.8 \%$ of the respondents. This analysis includes a category called "other" that accounts for $15.8 \%$ of the respondents. For example, destruction of framed walls, damage to toilets, stolen or destroyed plans, and driving over graded site work were included in these acts of vandalism. Damage to construction equipment and damage to vehicles accounted for $9.2 \%$ and $6.6 \%$ respectively.

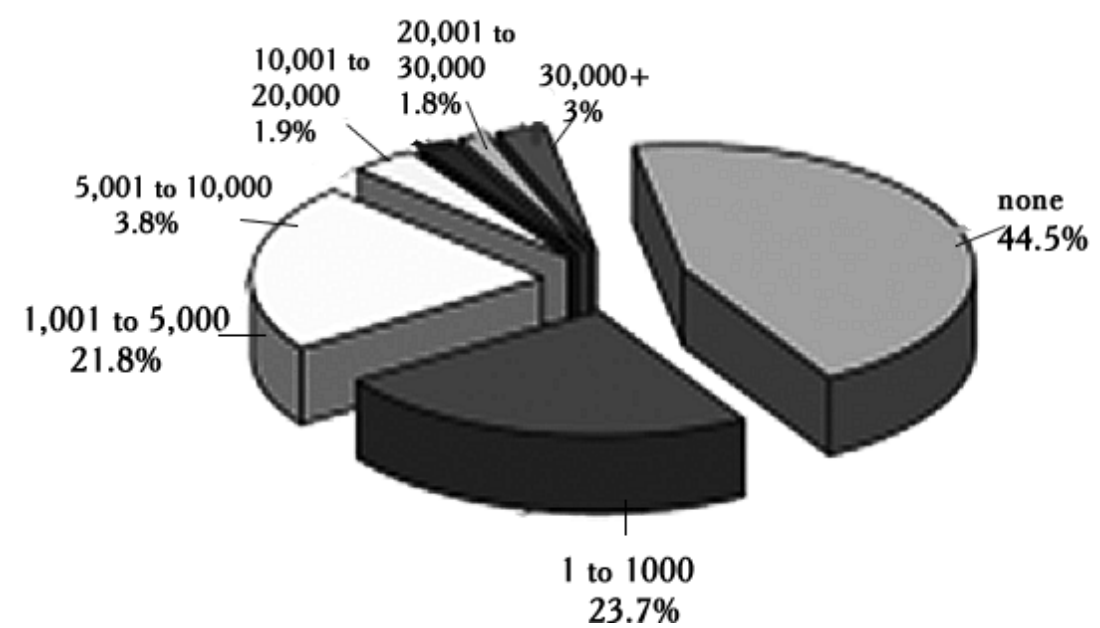

Fig. 1. Estimated total losses due to vandalism in the past 3 years

(Adopted from Montealegre, 2003)

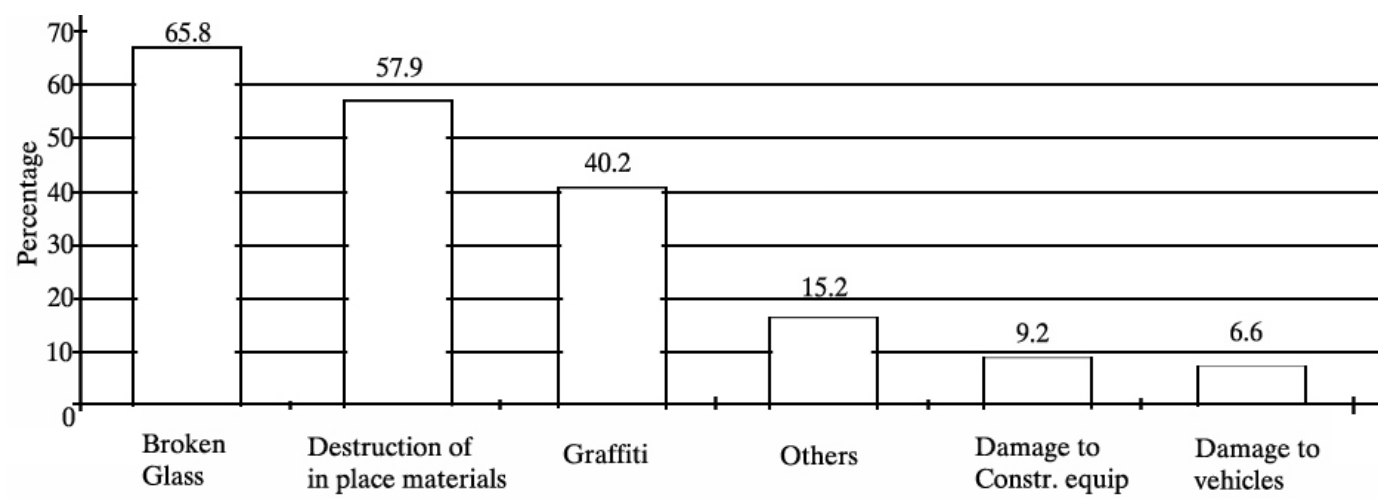

Fig. 2. Vandalism by type

(Adopted from Montealegre, 2003) 


\subsection{Security and loss control}

Theft of equipment range from office tools to heavy equipment on building sites. Most of these financial loss incurred by theft acts are been offset by the insurance while all uninsured costs are been incurred by project owners. These costs include insurance deductibles, replacing depreciated equipment with new equipment, and production delays, paperwork and time in reporting and replacing stolen equipment. Sometimes these uninsured costs often exceed the cost paid by insurance and add to contractors' overall operating expenses (Larry, 2003).

A recent form of theft that has been on the rise is the occurrence of office equipment theft from jobsite offices. Popular equipment that has attracted thieves includes fax machines, computers, copiers, and telephones. It is recommended that a company should try to position the site or trailer office in an area with limited access to the opportunist thief, yet highly visible to the public (Contractors' equipment, 2001). All expensive pieces of office equipment should be well marked with indelible markings. Valuable business information such as payroll figures, work schedules and future ventures, or anything that could undermine a company's strategy if lost or put in the hands of rivals should also be recognized as a potential target and protected accordingly (www.Neighborhoodwatch.Net, 1992).

In addition to getting away with tools and heavy equipment, computers and fax machines in site offices have been a target of thieves. With computers playing a significant operational role, the theft of a computer can seriously impact the company's ability to conduct business (Bond, 2000). Loss to theft of such equipment causes contractors to turn in insurance claims that eventually will cause insurance premiums to increase.

Before implementing a jobsite security plan, a company should consider its business history of recurring theft problems (how much has the company typically lost on past projects to thieves), the locality where the work is being done must also be taken into account when assessing the performance of a particular building site security plan. Regarding building site security, the role played by location is evident and an important risk factor in recent research dealings with theft and vandalism (McDowall, 2002).

Loss of construction equipment from theft makes construction projects more expensive. As the potential losses increase, the company's investment in security should also increase (Larry, 2003). The political aspects of the project must also be weighed. Is the job controversial? Is there a history of crime in the area? The answers to these questions will help the company determine the type and amount of security required to reduce the attractiveness of a construction site for theft (Lumberman's of Washington, Inc., 2000).

To combat equipment theft, Liberty Mutual Insurance's Loss, prevention department recommends permanently etching on equipment (spray paint and initials on a piece of equipment does not qualify as being "positively" identified). It also suggests asking for identification from drivers before equipment is loaded onto lowboys, and removing keys and securing the jobsite at the end of the day. One should also immobilize equipment when it is not in use; this can be done by removing rotors, lowering blades and buckets, and disabling batteries and electric starting systems Bonesteel, (1997) cited in Berg, (2003).

Another approach is use of security video combined with wireless communication to an off-site monitoring station or directly to construction manager's laptop, this allows the manager to look up from his desk to see what is going on site, inventory equipment frequently and installing anti-theft devices such as fuel cutoffs, hydraulic bypasses, track locks or specifically contacting equipment dealers for particular anti-theft devices developed for their products (Bill, 2008).

Another important factor that is needed to be taken into account when dealing with security on construction projects is the reporting of any incident that involves the theft and vandalism of heavy equipment, tools or materials. According to Farinloye et al., (2009) theft appears to be a greater problem in the construction industry compared to vandalism as the industries have a tendency to take theft more seriously than vandalism, reporting nearly all the cases of theft that occur on their sites. On the other hand, vandalism reports are significantly lower. The reason why the frequency of theft reporting by construction firms/ contractors is higher than the reporting of vandalism cases is because theft is a more damaging, costly phenomenon, losing equipment and construction materials cost hundreds of thousands. Reporting of crime is beneficial to everyone involved, as well as potential future victims, when local law enforcement is made aware of the occurrence of every incident of theft and vandalism. This will enable law enforcement to patrol more effectively and to be able to work at assisting contractors in locating the stolen equipment. When reporting an incident, one should include as much detail as possible; including year, make, model, serial numbers, company identification (e.g. logos, decals, internal numbers, unique paint), and any attachments or customized features to assist the authorities in trying to locate a piece of stolen equipment (Bonesteel, 1997).

According to Danek (2000) to prevent theft of tool and equipment on construction site is difficult especially on larger construction site. In most companies there appears no provision for the appointment of a crime prevention agencies or similar position to coordinate action. Responsibility for losses generally falls to the construction manager or building supervisor who has responsibility for security as an addition to their primary role. Crime prevention principles identify that everyone has a responsibility to take reasonable precautions to prevent crime and look after their property. Implementing crime prevention strategies to minimize the risk and incidence of construction site theft and vandalism could make considerable progress in providing co-ordinated action. A possible model for coordinated action could be drawn to address various building security issues including investigating, reporting, coordinating, implementing and evaluating a whole range of crime prevention strategies and security control for the building industry (BSCP, 2002).

\subsubsection{Security prevention awareness}

\subsubsection{Camera security system}

Installed Cameras system are motion sensitive and infrared enabled with the use of digital video recorder 
(DVR) camera device that accept analog signal from security camera, converting it to digital format allows setting of motion detection features and alert off site monitoring when activated, though, this could be a highly cost effective way to secure a project. Monitoring staff can then look at vision from the site and make a decision whether to alert a roving patrol responder to attend (Steve, 2008).

\subsubsection{Staff crime security awareness}

It is important that security measures are discussed at top level and that all senior staff fully understands the implications of poor security. Good control of staff and vehicles on site is essential. Security staff should regularly check and search all employees, lockers and contractors' vehicles. Employees' private vehicles should be kept off the site. There are a number of measures that should be taken to raise staff awareness of security (Dumfries and Galloway, 2004):

- Make individual members of staff personally responsible for company equipment they use.

- Make sure that everyone on site knows the company policy on crime management and is familiar with site security procedures.

- Tell everyone that you expect them to report suspicious incidents and that everything they say will be treated in confidence.

- If any plant is stolen, you should report the theft immediately to the local police, giving them as much information as possible about the missing item - including all serial numbers.

Due to recent activity concerning theft and vandalism on building sites, Crime Analysis Unit of El Dorado County Sheriff of California, USA came up with the following information to assist those at risk (Crime Alert, 2006).

- Minimize the time that building materials and tools are left unattended.

- If expensive equipment is left on-site after hours consider hiring security personnel.

- Plan to have appliances and materials delivered and installed on the same day.

- Install expensive "high risk" items as close to hand over as possible.

- Clearly display the lot number, the name of the builder and an afterhours contact number on all construction sites.

- Erect warning signage about building site crime on housing estates and individual dwellings.

- Identify and mark all materials and appliances.

- Liaise with surrounding neighbours and inform them about any development in the area.

- Distribute "open letters" to residents.

- Arrange with the local council for street lighting to be installed and operating on the day that construction commences.
- Inform the police about the construction and provide them with afterhours contact details.

- Encourage construction workers to liaise with other builders and consider establishing a reference group to address security issues.

\subsubsection{On-site security}

To discourage theft, you can permanently mark your company's property for quick visual identification. The most common way of marking items is to use coloured paint. Some paints have additives to distinguish them from other paints. Stamping, etching, engraving, sandblast marking, acid pens or ultraviolet lacquer can also be used to permanently mark property. The Utilities Plant Theft Scheme (UPTS) has a system which records details of members' stolen plant and equipment on computer. The scheme also runs periodic stock checks of hired plant and records the details. Any cross-matches are referred to the relevant companies for further enquiries and, if necessary, to the police for investigation. Computer reports on stolen and recovered plant are available to all members and the police.

A wider adoption of the Vehicle Identification Number (VIN) and Product Identification Number (PIN) scheme could also help in combating plant theft, making machinery easily identifiable and undermining the lucrative second-hand stolen plant market (City of Irvine, n.d.). VINs are issued by the British Standards Institution encourages everyone on site to mark all their tools and keep a list of all VINs as well as serial and engine numbers. This gives the police a better chance of getting them back if they are lost or stolen and it also prevents arguments over which tools belong to whom. Tools left on site overnight should be kept in locked security tool stores (using close-shackled padlocks).

In the interest of preventing theft on site the following rules apply :

- Lock up all your tools when you are not using them.

- Clearly mark all your property.

- Remove ignition keys from all unattended plant.

- Immobilize all plant when not in use

- Whenever possible, park vehicles off the road at night and weekends.

- Return all keys to the Site Manager or whoever is responsible for the keys.

- If you have been given a security pass - wear it!

- Report any thefts or suspicious behaviour immediately to your Site Manager.

\subsubsection{Perimeter protection}

Security fencing is the best form of perimeter protection, and exits and entrances should be kept to a minimum. It is best to place the reception area near the main gate and you could also consider employing security guards. Companies working in areas where there is good natural surveillance may find it better to use the weld mesh-type fencing panels rather than the solid boarded type - which would enable the public to report anything that looks suspicious. 
According to City of Irvine in construction site security requirements;

- Number of access points shall be minimized

- Fencing shall be installed around the site perimeter adjacent to streets

- Vehicle and pedestrian gates and all openings to jobsite shall have their gates secured after hours of operation.

Other obvious safeguards are:

- Lighting: good portable lights help ensure good visibility within working hours. Floodlights operated by sensors could also be installed.

- Vehicle gate locations shall be illuminated during hours of darkness

- Minimum light level at required locations is one footcandle at the ground for fifteen foot radius

- Projects requiring a security plan, information sheets containing security light fixtures should be submitted.

- CCTV and Alarm Systems: either standalone or integrated, should be used to protect the security compounds and offices.

- Warning Notices: stating that security precautions are enforced around the perimeter, without providing details.

\subsubsection{Site arrangement}

Try to position the site office in an area with limited access for the opportunist thief. Office equipment such as fax machines, computers and telephones are all expensive and can easily be stolen if not properly secured. They should be well marked with indelible marking - for example by branding the company logo and postcode onto the equipment. Also consider protecting valuable business information. This could include payroll figures, work schedules and future ventures, or anything that could undermine your company strategy if it was lost or put in the hands of rivals. To discourage theft, you can permanently mark your company's property for quick visual identification. Stamping, etching, engraving, sandblast marking, acid pens or ultraviolet lacquer can be used.

When ordering plant from a hire company, always makes sure that there will be a responsible person on-site to accept delivery. Be wary of anyone offering plant for sale, particularly if they have no proof of ownership - most major plant firms paint their equipment in their own particular colours. If the site is not protected by perimeter fences, plant should be kept in a security compound and immobilized, using one of the security locks, rings or ground fixings that are available.

Order the minimum amount of materials you need and, as with any deliveries, make sure that there is someone trustworthy on site to accept them. If you have to order materials in bulk, store them in a secured compound or in an area where theft will be noticed quickly. Some security outfits are known to install security devices on site to prevent site theft and it would be important for construction companies to build partnership with these security outfits to combat crime on site.

\section{Research Methods}

The study examined the causes and incidence of theft and vandalism, causes of losses and measures to be employed to eliminate thefts and acts of vandalism on construction site. The study population was based on the following classification of construction firms' i.e. Large Construction, Medium Construction and Small Construction Firms in Lagos state. The opinion survey questionnaires were administered on the three classes of construction firms. Construction professionals were limited to Builders, Civil Engineers, Quantity Surveyors, and Project Managers that are engage with building project under construction.

The method used for sampling was purposive because population of relative limited group of building professionals was studied. 42 questionnaires were completed out of the 120 questionnaire representing a $35 \%$ response rate posted out to gathered responses from building professionals.

The questionnaire addresses years of respondents experience, annual volume of work performed in Nigeria currency Naira $(\mathrm{N})$, theft and vandalism occurrence in the past five years, estimated loss $(\mathrm{N})$ to theft and vandalism acts in the past five years, preventive measures to theft of tools/equipment, causes of losses on building sites and component of security on building site.

The data collected was analyzed using statistical package for social sciences (SPSS) so as to obtain a comprehensive and accurate analysis in both the descriptive statistic and inferential statistics as applicable.

\section{Discussion of Findings}

\subsubsection{Respondents experience in the construction industry}

$9.5 \%$ of the respondents in Lagos, Nigeria have less than 10 years of experience. $21.4 \%$ indicated that their year of experience is between 10 and 20 while largest proportion of $69 \%$ indicated to have more than 20 years of experience as presented in Table 1.

Table 1. Respondents experience across the three categories

\begin{tabular}{ccc}
\hline Years of experience & Percentage $\%$ & frequency \\
\hline$<10$ & 9.5 & 4 \\
$1-20$ & 21.4 & 10 \\
$>20$ & 69 & 29 \\
Total & 100 & 42 \\
\hline
\end{tabular}




\subsubsection{Volume of work performed by the firms}

The annual volume of work performed in relation to the three categories of construction firms; small, medium and large size. Twenty seven firms $(64.23 \%)$ are in large category with $\mathrm{N} 20,000,000,000$ and above worth of annual volume of work performed. Ten $(23.8 \%)$ and five $(9.52 \%)$ firms are in medium and small size categories with annual volume of work performed of N1,000,000,000-N20,000,000,000, and below N1,000,000,000 respectively (see Fig. 3).

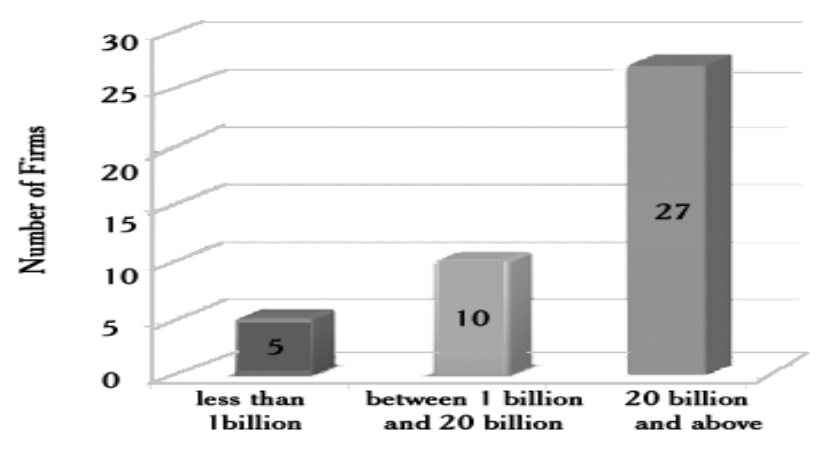

Annual Naira Volume of work Performed

Fig. 3. Annual Naira volume of work

\subsubsection{Theft Incidents in the five year}

Theft incidents in the past 5 years as experienced by firms on building sites are shown in Fig. 4.24 firms (57.1\%) of the 42 firms experienced less than 10 theft incidents in the past five years, 15 (35.7\%) firms experienced between 10 and 20 theft incidents, 2 firms also experienced between 20 and 50 while only one firm signified to have experienced more than 50 theft incidents in the past five years.

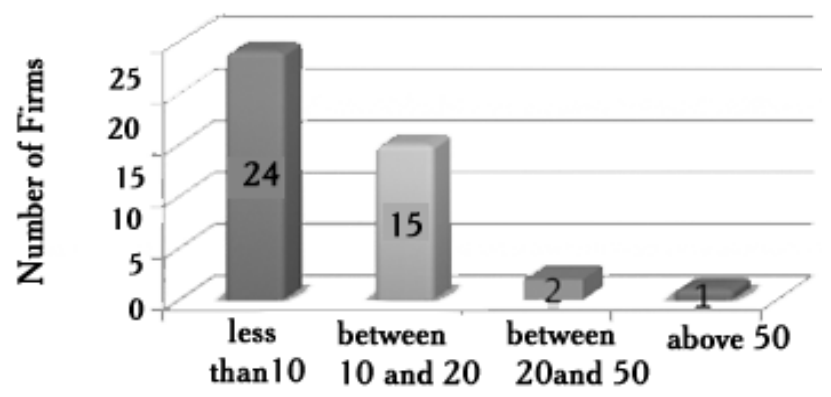

\section{Number of Theft incident}

Fig. 4. Number of theft incident

\subsubsection{Estimated total theft loss in the past five years}

In the past five years twenty two firms $(53.7 \%)$ revealed to have experienced less than $\mathrm{N} 1,000,000$ estimated losses to theft, 16 firms (39\%) experienced theft loss of between $\mathrm{N} 1,000,000$ and $\mathrm{N} 10,000,000$ while 3 firms (7.3\%) also experienced an estimated loss N10,000,000 and above (see Fig. 5).

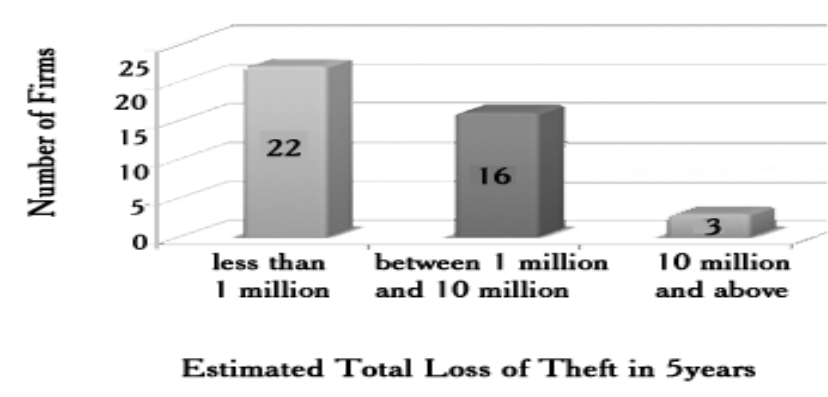

Fig. 5. Estimated total theft loss

\subsubsection{Volume of Work Performed and Theft Incidents}

Table 2, presents the number of theft incidents experienced by the different category of firms' i.e. large, medium and small firms in the past five years. It is revealed that small firms experienced less number of theft incidents compare to medium and large firms. Three out of the five small firms recorded less than ten theft incidents while the remaining two small firms recorded maximum theft incidents within the range of ten to twenty. Medium firms are ten in numbers, five medium firms recorded less than ten theft incidents, four medium firms recorded theft incidents within the range of ten to twenty and one medium firm recorded between twenty to fifty number of theft incidents. Large firms experienced large number of theft incidents, out of the twenty seven large firms sixteen firms experienced less than ten theft incidents, nine firms experienced between ten and twenty theft incidents, one firm recorded between twenty to fifty number of theft incidents and another one firm also experienced theft incidents above fifty.

\subsubsection{Volume of work performed and estimated total loss to theft}

In line with what was obtained in number of theft incidents and size of firms (see Table 3), the small firms incurred lower loss when compared to the large firms. For 5 years emphatically, four small firms i.e. $(80 \%)$ incurred less than $\mathrm{N} 1,000,000$, five medium firms i.e. (50\%) incurred less than $\mathrm{N} 1,000,000$ and thirteen large firms $(50 \%)$ also incurred less than N1,000,000. One small firm $(20 \%)$, four medium firms $(40 \%)$ and eleven large firms (42.3) incurred an estimated loss of N1,000,000 $\mathrm{N} 10,000,000$, One medium firm $(10 \%)$ and two large firms (7.7\%) incurred an estimated loss between N10,000,000 and above.

\subsubsection{Vandalism incidents in the past five year}

Fig. 6 shows that 34 firms $(81 \%)$ out of the 42 firms experienced less than 10 vandalism incidents while the 8 firms (19\%) experience between 10 and 20 vandalism incidents. This implies that vandalism incident is uncommon on building sites in Lagos, Nigeria. 


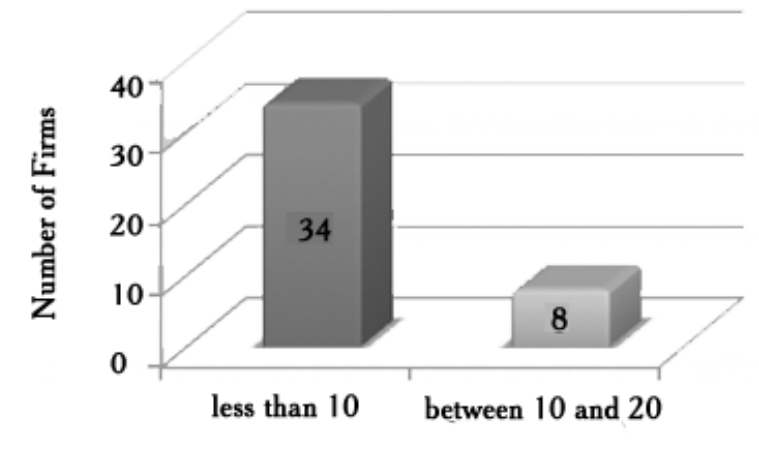

Number of Vandalism incidents in the past 5 years

Fig. 6. Vandalism incidents

\subsubsection{Estimated vandalism loss}

The total estimated loss to vandalism shows 24 (58.5\%) firms having between N1,000,000 and N10,000,000 loss. This implies that this range of loss value is incurred by more than half population of the firms in the past 5 years. 14 firms $(33.3 \%)$ of the total number of firms had total estimated loss of less N1,000,000 while 3 (7.1\%) firms had up to N10,000,000 and above total estimate loss (see Fig. 7).

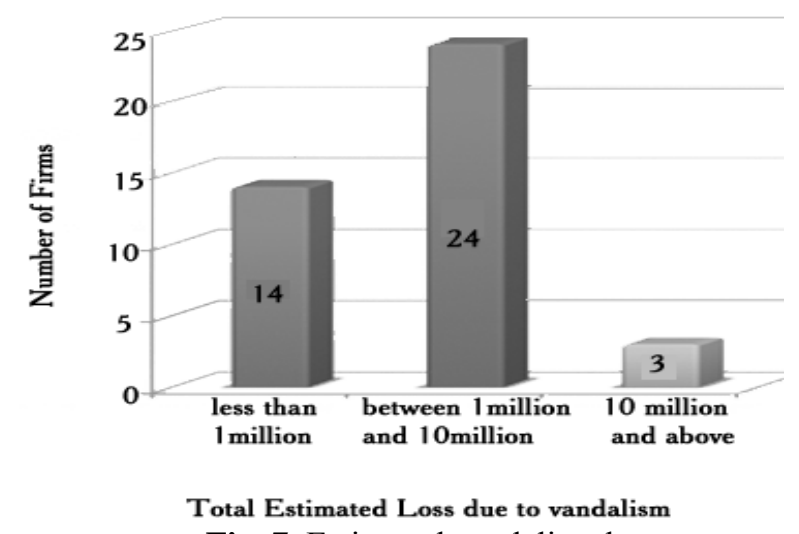

Fig. 7. Estimated vandalism loss

\subsubsection{Volume of work performed and vandalism incidents}

Number of vandalism incidents experienced by firms according to their size as evaluated based on the annual work performed shows that three out of the five small firms recorded less than ten vandalism incidents while the remaining two small firms recorded vandalism incidents within the range of ten to twenty. Medium firms are ten in numbers, nine medium firms recorded less than ten vandalism incidents and one remaining medium firm recorded between ten to twenty number of vandalism incidents. Twenty two firms out of the twenty seven large firms experienced less than ten vandalism incidents while five firms experienced between ten and twenty vandalism incidents as explained in Table 4.

Table 2. Category of firms and theft incidents

\begin{tabular}{|c|c|c|c|c|c|}
\hline \multirow[t]{2}{*}{ Volume of Work Performed in (Naira) } & \multicolumn{4}{|c|}{$\begin{array}{l}\text { Number of Theft } \\
\text { Incident }\end{array}$} & \multirow[t]{2}{*}{ Total } \\
\hline & $\begin{array}{c}< \\
10\end{array}$ & $\begin{array}{l}10- \\
20\end{array}$ & $\begin{array}{c}20- \\
50\end{array}$ & $\begin{array}{l}> \\
50\end{array}$ & \\
\hline Less than One billion & 3 & 2 & 0 & 0 & 5 \\
\hline Between One billion and twenty billion & 5 & 4 & 1 & 0 & 10 \\
\hline Twenty billion and above & 16 & 9 & 1 & 1 & 27 \\
\hline Total & 24 & 15 & 2 & 1 & 42 \\
\hline
\end{tabular}

Table 3. Volume of Work and estimated loss to theft

\begin{tabular}{|c|c|c|c|c|}
\hline \multirow{2}{*}{$\begin{array}{c}\text { Volume of work } \\
\text { performed in } \\
\text { Naira }\end{array}$} & \multicolumn{3}{|c|}{$\begin{array}{l}\text { Estimated Total Loss of Theft in the } \\
\text { past } 5 \text { years }\end{array}$} & \multirow[t]{2}{*}{ Total } \\
\hline & $\begin{array}{l}\text { Less than } \\
\text { One million }\end{array}$ & $\begin{array}{l}\text { One million - } \\
\text { Ten million }\end{array}$ & $\begin{array}{l}\text { Ten million } \\
\text { and above }\end{array}$ & \\
\hline $\begin{array}{l}\text { Less than } \\
\text { One billion }\end{array}$ & 4 & 1 & 0 & 5 \\
\hline $\begin{array}{l}\text { Between One billion and } \\
\text { Twenty billion }\end{array}$ & 5 & 4 & 1 & 10 \\
\hline $\begin{array}{l}\text { Twenty billion } \\
\text { and above }\end{array}$ & 13 & 11 & 2 & 26 \\
\hline Total & 22 & 16 & 3 & 41 \\
\hline
\end{tabular}


Table 4. Volume of work performed and number of vandalism incidents

\begin{tabular}{llll}
\hline \multicolumn{1}{c}{ Volume of Work Performed in Naira } & $\begin{array}{c}\text { Number of Vandalism Incidents } \\
\text { in the past 5 years }\end{array}$ & Total \\
\cline { 2 - 3 } & \multicolumn{2}{c}{$10-20$} & $5(100 \%)$ \\
Less than One billion & $3(60 \%)$ & $2(40 \%)$ & $10(100 \%)$ \\
Between One billion and twenty billion & $9(90 \%)$ & $1(10 \%)$ & $27(100 \%)$ \\
Twenty billion and above & $22(81.5 \%)$ & $5(18.5 \%)$ & $42(100 \%)$ \\
Total & $34(81 \%)$ & $8(19 \%)$ & $40 \%)$ \\
\hline
\end{tabular}

Table 5. Volume of Work Performed and Estimated Total

Loss to due to Vandalism

\begin{tabular}{|c|c|c|c|c|}
\hline \multirow[t]{2}{*}{$\begin{array}{c}\text { Volume of } \\
\text { Work Performed in Naira }\end{array}$} & \multicolumn{3}{|c|}{$\begin{array}{c}\text { Estimated Total Loss in Naira due to } \\
\text { Vandalism in the past } 5 \text { years }\end{array}$} & \multirow[t]{2}{*}{ Total } \\
\hline & $\begin{array}{l}\text { Less than } \\
\text { One million }\end{array}$ & $\begin{array}{l}\text { One million - } \\
\text { Ten million }\end{array}$ & $\begin{array}{l}\text { Ten million } \\
\text { and above }\end{array}$ & \\
\hline Less than & 3 & 2 & 0 & 5 \\
\hline One billion & & & & \\
\hline Between One billion and twenty billion & 4 & 6 & 0 & 10 \\
\hline $\begin{array}{l}\text { Twenty billion } \\
\text { and above }\end{array}$ & 7 & 16 & 3 & 26 \\
\hline Total & 14 & 24 & 3 & 41 \\
\hline
\end{tabular}

\subsubsection{Volume of work performed and estimated total loss to vandalism}

The estimated value of total loss to vandalism in the past five years for different size of firms indicates high value of loss for medium and large firms when compared to small firms. Estimated loss that is less than $\# 1,000,000$ is incurred by three small firms $(60 \%)$, four medium firms $(40 \%)$; seven large firms $(26.9 \%)$. While an estimated loss between N1,000,000 and N10,000,000 is incurred by two small firms $(40 \%)$, six medium firms $(60 \%)$ and six large firms $(61.5 \%)$. Also three medium and three large firms incurred N10,000,000 and above. It implies that more proportion of large firms experienced higher total estimated loss due to vandalism for the past 5 years as explained in Table 5.

\subsubsection{Suspected identity of vandals}

$9(21.4 \%)$ out of 42 firms experienced graffiti in the past 3 years.

$24(57.1 \%)$ out of 42 firms experienced an incident of broken glass on construction site.

$30(71.4 \%)$ are found to have experienced incidents of destruction of in-place materials. 23 (54.8\%) firms indicated they experienced incidents of damage of licensed vehicles.

$27(64.3 \%)$ firms also experienced incidents of damage to construction equipment.

Those that were identified as suspect of vandalism on construction jobsite are disgruntled workers and workers who had been fired are the suspects of Vandalism.

\subsection{Security measures}

\subsubsection{Measures used to prevent the theft of tools on the construction site}

Fig. 8 shows estimated theft loss of each of the preventive measures adopted by the firms.

It is observed that "minimizing of tools left on site" and "provision of tools by workers" are the least types of measure used on site. The predominant measures are maintenance of tool inventory, marking of tools, maintenance of secured storage area and making workers responsible for tools. This finding conforms to Berg (2003) study on measures used in preventing theft of tools on sites. The loss associated with each of the preventive measures is largely a combination of less than N1,000,000 and between N1,000,000 and N10,000,000. Loss worth $\mathrm{N} 10,000,000$ or more is found to be uncommon, especially when "marking tools" is used as preventive measure. The chart shows proportion of firms that incurred a loss that is less than $\mathrm{N} 1,000,000$ being higher than those that incurred between N1,000,000 and N10,000,000 for preventive measures such as; using maintenance of tool inventory, marking tools, maintenance of secured storage area, and making workers responsible for tools. On the other hand, this proportion is lower for minimizing tools left on site but with equality in provision of tools by workers.

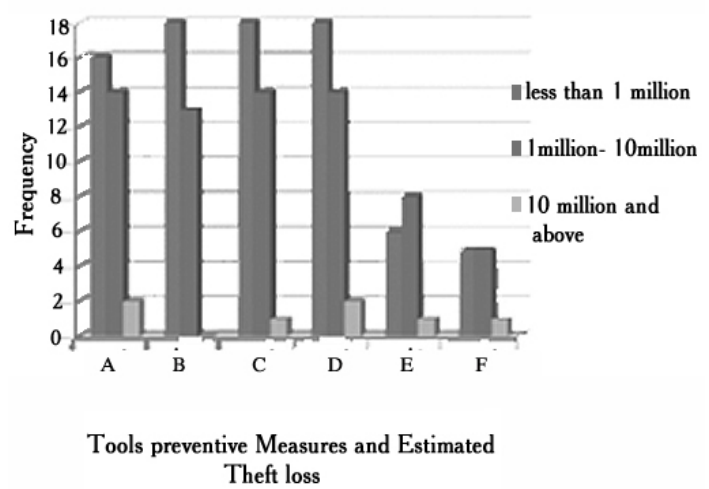

Fig. 8. Tool preventive measures 

A : Maintaining tool inventory
B: Marking of tools
C: Maintaining a secure storage area
D: Making workers responsible for tools
E: Minimising tools left on site
F: Worker to provide their own tools

\subsubsection{Machinery and equipment theft preventive measures on the construction site}

The adoption of most of the machinery and equipment preventive measures by the firms are relatively same except for "use of distinctive colour for the equipment" and "parking the equipment at a central location". In "use of distinctive colour for the equipment", the theft loss incurred is not above N10,000,000 while in "parking the equipment at a central location" theft loss incurred is less than $\mathrm{N} 1,000,000$ and between N1,000,000 to N10,000,000 are of equal proportion of number of firms.

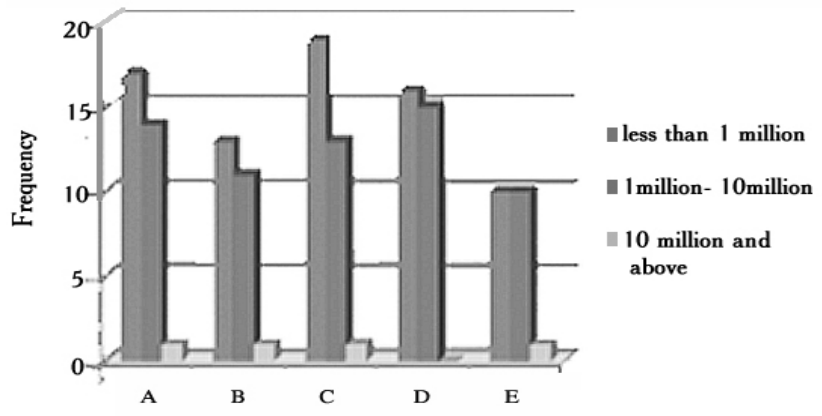

Machinery and Equipment Preventive Measures and estimated Theft Loss

Fig. 9. Machinery and equipment preventive measures

A: Parking of equipment and machinery in a well-lighted area

B: Modifying the ignition of fuel lines

$\mathrm{C}$ : Including additional identification on equipment and machinery

D: Using a distinctive color to mark equipment and machinery

E: Parking of equipment in a specific formation at the end of the day

\subsubsection{Importance of component of security}

To be able to quantify the degree of importance of component of security and level of agreement to causes of losses on construction site, the author used the following average index on rating scale 1-5.

Rating scale for importance of component security and level of agreement to causes of losses on building sites

- $1.00 \leq \mathrm{AI}<1.50$ means unimportant/ disagree

- $1.50 \leq \mathrm{AI}<2.50$ means slightly important/ slightly disagree

- $2.50 \leq \mathrm{AI}<3.50$ means moderately important/partially agree

- $3.50 \leq \mathrm{AI}<4.50$ means important/agree

- $4.50 \leq \mathrm{AI} \leq 5.00$ means very important/strongly agree
Yulia 2008 study on two construction building projects (telkomsel telecommunication and West Sumatra Great mosque) revealed that component of physical, personnel, information security, and security awareness are very important to construction works while investigation security component are important.

The results shows degree of importance of component of security; security officer on site are to be trained and motivated to curb theft and vandalism, document and valuables information such as payroll figures, work schedules, computers, fax machines e.t.c. are to protected, pre - employment screening exercise to verify status of workers. The results in Table 6 demonstrate that all components of security are of importance. This is evidenced in Table 6 as no respondents see any of the components of security to be unimportant.

All security components are considered to be important (4 rating scale) by all the construction professionals.

- Personnel security (4.14 average index; category rating scale of 4)

- Information security (4.07 average index; category rating scale of 4 )

- Investigation security (4.00 average index; category rating scale of 4)

- Security awareness (3.98 average index; category rating scale of 4)

- Physical security 1and 2 (3.90 and 3.57 average index; category rating scale of 4$)$

\subsubsection{Causes of Losses at Construction Site}

The level of agreement with the causes of losses on construction site are rated and presented in Table 7. The result revealed level of agreement as, "Agree", to all causes of losses on construction site.

- Discharging or laying off employee in an inappropriate manner (4.05 average index; category rating of 4)

- Vandalism act by both internal \& external people (4.02 average index; category rating of 4)

- Night time and breaks observed during construction (4.02 average index; category rating of 4)

- Theft involving employees on site (4.00 average index; category rating of 4)

- Theft and loss of heavy equipment, tools, materials \& office equipment (3.93 average index; category rating of 4)

- No structured security procedure (3.90 average index; category rating of 4)

- Non - use of security tool like CCTV, alarm system on site (3.90 average index; category rating of 4)

The result is not out rightly different from the study conducted by Yulia (2008), her study found out that respondents agree to some identified causes of losses on construction site like poor site storage \& poor check in/out system, theft and loss of heavy equipment, tools, materials \& office equipment, vandalism act by both internal \& external people, and discharging or laying off employee in an inappropriate manner among others except no clearly 
defined roles \& duties of security officers, inadequate lighting at night, insufficient security support, and non use of CCTV \& alarm system on site that are rated on scale of partially agree and no clearly security procedures rated on a scale of slightly disagree by the respondents.

Table 6. Components of sites security

\begin{tabular}{|c|c|c|c|c|c|c|c|c|}
\hline & Security & & que & f R & ond & & Average & Category of \\
\hline & Components & 1 & 2 & 3 & 4 & 5 & index & rating scale \\
\hline 1 & $\begin{array}{l}\text { Physical Security (1): All construction sites } \\
\text { shall at least meet the minimum security } \\
\text { standards }\end{array}$ & 0 & 5 & 16 & 13 & 8 & 3.57 & 4 \\
\hline 2 & $\begin{array}{l}\text { Physical Security (2): All tools, equipment } \\
\text { and materials shall have marked on the site, } \\
\text { have a check out/in system, if not in use will } \\
\text { be secured and stored in a proper } \\
\text { place/warehouse to prevent theft or loss }\end{array}$ & 0 & 4 & 9 & 17 & 12 & 3.90 & 4 \\
\hline 3 & $\begin{array}{l}\text { Personnel Security: Trained and motivated } \\
\text { security officers need to secure construction } \\
\text { site from theft and all criminal action that } \\
\text { possibly occur, moreover if the site is in the } \\
\text { non-secure area }\end{array}$ & 0 & 2 & 5 & 21 & 14 & 4.14 & 4 \\
\hline 4 & $\begin{array}{l}\text { Investigation Security: Pre-employment } \\
\text { screening investigations is used to verify the } \\
\text { applicants relating to their employment, } \\
\text { education and criminal history background }\end{array}$ & 0 & 2 & 7 & 22 & 11 & 4.00 & 4 \\
\hline 5 & $\begin{array}{l}\text { Security Awareness: All of contractor } \\
\text { personnel including labor at project site } \\
\text { should be aware of the importance of security }\end{array}$ & 0 & 2 & 12 & 13 & 15 & 3.98 & 4 \\
\hline 6 & $\begin{array}{l}\text { Information Security: All of document or } \\
\text { information including computer networks at } \\
\text { project site should be protected and it is a } \\
\text { necessary part of site security plan. }\end{array}$ & 0 & 2 & 7 & 19 & 14 & 4.07 & 4 \\
\hline
\end{tabular}

Note: rating scale used are as follows: $1=$ Unimportant, $2=$ Slightly Important, $3=$ Moderately Important, $4=$ Important and $5=$ Very Important.

Table 7. Causes of Losses on sites

\begin{tabular}{|c|c|c|c|c|c|c|c|c|}
\hline & \multirow[t]{2}{*}{ Causes of Losses } & \multicolumn{5}{|c|}{ Frequency of Respondents } & \multirow{2}{*}{$\begin{array}{l}\text { Average } \\
\text { index }\end{array}$} & \multirow{2}{*}{$\begin{array}{l}\text { Category of } \\
\text { rating scale }\end{array}$} \\
\hline & & 1 & 2 & 3 & 4 & 5 & & \\
\hline 1 & $\begin{array}{l}\text { Theft or loss of equipments, tools, material } \\
\text { and office stuffs are the main problems of site } \\
\text { security problems. }\end{array}$ & 0 & 0 & 7 & 31 & 4 & 3.93 & 4 \\
\hline 2 & $\begin{array}{l}\text { Vandalism can be doing by external and } \\
\text { internal person or group }\end{array}$ & 0 & 0 & 11 & 19 & 12 & 4.02 & 4 \\
\hline 3 & $\begin{array}{l}\text { Theft occasionally involving employees or } \\
\text { labor within the project }\end{array}$ & 0 & 0 & 8 & 26 & 14 & 4.00 & 4 \\
\hline 4 & $\begin{array}{l}\text { In the night, holiday or out of hours working, } \\
\text { are the best time to the thieves doing the theft }\end{array}$ & 0 & 1 & 13 & 2 & 16 & 4.02 & 4 \\
\hline 5 & $\begin{array}{l}\text { Poor site storage and poor check out/in system } \\
\text { for tools and materials can improve } \\
\text { opportunity for the theft and loss }\end{array}$ & 0 & 2 & 17 & 14 & 10 & 3.79 & 4 \\
\hline 6 & $\begin{array}{l}\text { Discharge of the employee if not doing by } \\
\text { appropriate procedure can raise a problem to } \\
\text { the company }\end{array}$ & 0 & 0 & 11 & 17 & 13 & 4.05 & 4 \\
\hline 7 & $\begin{array}{l}\text { No clearly defined roles and duties for the } \\
\text { security officers }\end{array}$ & 0 & 3 & 10 & 22 & 7 & 3.70 & 4 \\
\hline 8 & No adequate lighting in the night & 1 & 2 & 10 & 22 & 7 & 3.76 & 4 \\
\hline 9 & No clearly security procedures at the site & 0 & 2 & 11 & 17 & 11 & 3.90 & 4 \\
\hline 10 & $\begin{array}{l}\text { Not enough support to the security policy } \\
\text { from the senior management of the project }\end{array}$ & 0 & 5 & 14 & 18 & 5 & 3.55 & 4 \\
\hline 11 & $\begin{array}{l}\text { Not using security tools such as CCTV and } \\
\text { alarm system to protect site }\end{array}$ & 0 & 3 & 10 & 17 & 12 & 3.90 & 4 \\
\hline
\end{tabular}

Note: $1=$ Disagree, 2 = Slightly Disagree, 3 = Partially Agree, 4 = Agree, 5 = Strongly Agre 


\section{Conclusions}

The findings of this study reveal the importance of security for construction firms and it highlights the security issues affecting building projects under construction. According to results, $57.1 \%$ of firms experienced less than 10 theft incidents and $81 \%$ of firms experienced less than 10 vandalism incidents. Large firms are found to incur more loss than small and medium firms; loss per number of theft incident experienced is also higher in large firms.

The predominant theft measures on building sites are maintenance of tool inventory, marking of tools, maintenance of secured storage area and making each worker responsible for their tools.

More proportion of large firms experienced higher total estimated loss due to vandalism. Those that were identified as suspect of vandalism on construction jobsite are disgruntled workers and workers who had been fired are the suspect of vandalism.

Personal security and Information security is considered to be important with an average index above 4, while Investigation security, security awareness and physical security has same rating as being important. Firms in Lagos show same level of agreement, "Agree", to all causes of losses on construction site.

Every year construction company/building contractors loose huge money due to theft and vandalism. These losses will continue occurring unless appropriate precautions are taken which can make the difference between a company's success and its failure. It is essential that construction companies/ contractors report all losses due to vandalism or theft to the local police department or Security Company. Attention to be paid on the security of construction materials on site. Builders should minimize the time that materials are left on site before installing them and where and when possible enforce just-in-time deliveries. Also, they should focus on providing extra security especially when and where workers job are terminated to avoid vandalism.

Developing a good relationship with the neighbors has proven to be helpful in reducing theft and vandalism on site and if possible use a reward system.

\section{References}

Arata, M. (2006). Construction site security. 1st ed., McGraw Hill book company, New York.

Berg, R. (2003). Jobsite security on commercial construction projects. Master Thesis, Building construction, Graduate school, University of Florida, Florida.

Bergs, R. and Hinze, J. (2005). Theft and vandalism on construction site. Journal of construction engineering and management, 131(7), 826-833.

Bill, Z. (2008). Building construction site security. Available at: http://www.securitymagazine.com.

Bond, J. (2000). Contractors protect tools and equipment from theft. Atlanta Business Chronicle.

Bonesteel, M. (1997). NUCA, 8, 15-17.

Building Site Crime Prevention Initiatives (BSCP) (2002). Building site crime prevention initiatives. Final report, Author.
City of Irvine (n.d.). Construction site security requirements. Municipal code section 5-9-521.B. Available at: http://www.cityofirvine.org/civia/file bank/blobdload.asp?BlobID $=8795$.

Combating jobsite equipment theft (1986). Construction Site Theft. NUCA, 10(5), 20

Contractors' Equipment Losses (2001). Knowledge of Hazards Can Reduce Risk. Insurance Journal, 19, Available at: http://www.insurancejournal.com/ magazines/southcentral/2001/02/19/features/22326.ht $\mathrm{m}$.

Clark, R. and Goldstein, H. (2003). Reducing theft at construction site: lessons from problem-oriented project. crime prevention studies, 13, 89-130.

Cueno, C. (2001). Lock steady, Rental Equipment News.

Crime Alert. (2006). Preventing building site theft and vandalism. available at: http://www. neighbourhoodwatch.com.au/building/publicationsmai n.htm.

Danek, S. (2000). No construction site is immune from theft. Denver Business Journal, 52(70), 20.

Dumfries and Galloway (2009). Protect your building site, Crimestoppers.

Farinloye, O., Mafimidiwo, B., Adewunmi, Y. and Ajayi O. (2009). Prevalence of theft and vandalism on building site. Proceeding of the RICS COBRA Conference University of Cape Town, South Africa, 150-164.

Gardner, T. (2003). Security in Construction and Beyond, Protecting Your Site Even During Build-up. Available at: http://www.insideselfstorage.com/articles/291 feat4. html.

Lang, R. (2008). Health and safety on construction siteconstruction international. Available at: http://www. tag-guard.com.

Larry Barnet, P. (2003). Construction equipment security. In loss control best practices; Florida partnership for safety \& health.

Lumberman's of Washington, Inc. (2000). Available at: http://www.lumbermensbuilding.com/builders/builder xpress/BuildersXpressArticle.asp?Volume $=25 \&$ Articl $\mathrm{e}=1$.

McDowall, J. (2002). Backhoes, Air Compressors, Skidsteers, Generators Head the Hit List; Rental Management. Available at: http://www. rentalmanagementmag.com/newsart.asp?ARTID $=677$.

Montealegre, F. (2003). Jobsite security in residential construction. Master Thesis, Building construction, Graduate school, University of Florida, Florida.

Moorhouse, N. (2000). Cost Retention and Safety Enhancement, Protecting Your Assets. AGC of California. Available at: http://www2.agcca.org/services/SH\&E/Safety/Sb01-2.pdf.

Neighborhoodwatch Net. (1992). Site theft - A spanner in the works; Advice on construction site security. Available at: http://www.neighbourhoodwatch.net/ neighbourhoodwatch/organisational/prevention/site.

Pfeffer, S. (2002). Mark tools to cut theft at construction sites. Buffalo Business.

Premo, M. (n.d.). Construction site security white paper. US operations; EMZA visual sense. Available at: http://www.emza-vs.com/Construction Site Security_\%20white_paper.pdf-united states.

National Equipment Register (2002). The Problem of heavy equipment. Available at: www.nerusa.com. 
Rawl, J. (2000). Theft Prevention. Heavy Equipment News, 13(6), 36.

Steve, S. (2008). Digital video recorder security camera systems. Ezine articles.

Stewart, L. (2000). Firms discount equipment lost to crime. Construction Equipment, 101(4), 66-72.

Tamar, H. and David T. (2003). School vandalism: individual and social context. Adolescence, 38.

Yulia, S. (2008). Construction site security management and control. Master of Sciences Thesis, Faculty of civil engineering. Universiti Teknologi. Malaysia.

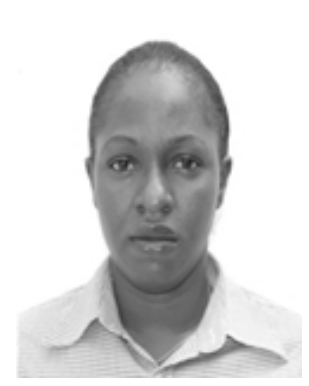

Farinloye Oluranti Olupolola is an

Assistant Lecturer in the Department of Building, Faculty of Environmental Science, University of Lagos, Akoka, Lagos State, Nigeria. She holds B.tech (Hons) in Building Technology and Msc. in Construction Management. She is a corporate member of the Nigerian Institute of Building (MNIOB). She is currently studying for her $\mathrm{PhD}$ Building (Construction Management) and her research interest includes Maintenance management, Facility management, Project and Performance management.

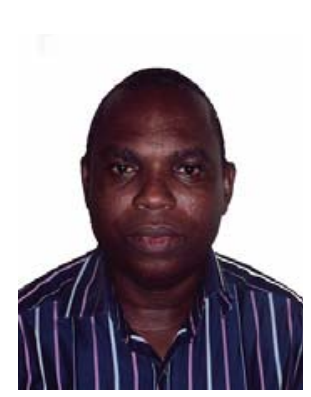

Odusami Koleola Tunwase is a Professor in the Department of Building, University of Lagos, Akoka, Lagos State, Nigeria. He holds Bsc (Hons) in Building Technology, Msc in Construction Management and $\mathrm{PhD}$ Building (Construction Management). Professor Odusami research interest includes Quantity surveying, Cost modeling, Construction management and Project management. $\mathrm{He}$ is a corporate member of Nigerian Institute of Building (MNIOB), registered member of council of registered Builder of Nigeria (CORBON), professional associate of the Nigerian Institute of Quantity Surveyors (MNIQS), registered Quantity Surveyor with the Quantity Surveyor Registration Board of Nigeria, Associate member of the Nigerian Institute of Management (AMNIM), Associate member of the American society of Civil Engineers (AMASCE), and professional member of the Royal Institute of Chartered Surveyors UK (MRICS).

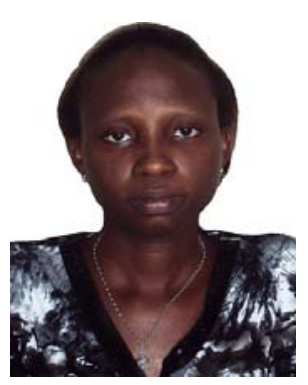

Adewunmi Yewande Adetoro is an assistant Lecturer in the Department of Estate Management, Faculty of Environmental Science, University of Lagos, Akoka, Lagos State, Nigeria. She holds Bsc (Hons) and Msc in Estate Management. She is an associate member of the Nigerian Institute of Estate surveyors and valuers. She is currently studying for her $\mathrm{PhD}$ in Estate Management, her research interest includes Facility management,
Benchmarking, Sustainability in facility management, and Information technology in Real estate. 